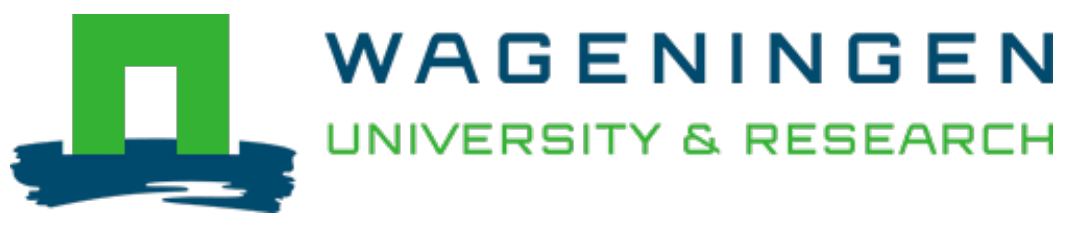

\title{
Towards the rose genome sequence and its use in research and breeding
}

Acta Horticulturae

Foucher, F.; Hilbrand-Saint Oyant, L.; Hamama, L.; Sakr, S.; Baudino, S. et al https://doi.org/10.17660/ActaHortic.2015.1064.19

This article is made publicly available in the institutional repository of Wageningen University and Research, under the terms of article $25 \mathrm{fa}$ of the Dutch Copyright Act, also known as the Amendment Taverne. This has been done with explicit consent by the author.

Article $25 \mathrm{fa}$ states that the author of a short scientific work funded either wholly or partially by Dutch public funds is entitled to make that work publicly available for no consideration following a reasonable period of time after the work was first published, provided that clear reference is made to the source of the first publication of the work.

This publication is distributed under The Association of Universities in the Netherlands (VSNU) 'Article $25 \mathrm{fa}$

implementation' project. In this project research outputs of researchers employed by Dutch Universities that comply with the legal requirements of Article $25 \mathrm{fa}$ of the Dutch Copyright Act are distributed online and free of cost or other barriers in institutional repositories. Research outputs are distributed six months after their first online publication in the original published version and with proper attribution to the source of the original publication.

You are permitted to download and use the publication for personal purposes. All rights remain with the author(s) and / or copyright owner(s) of this work. Any use of the publication or parts of it other than authorised under article $25 \mathrm{fa}$ of the Dutch Copyright act is prohibited. Wageningen University \& Research and the author(s) of this publication shall not be held responsible or liable for any damages resulting from your (re)use of this publication.

For questions regarding the public availability of this article please contact openscience.library@wur.nl 


\section{Towards the Rose Genome Sequence and Its Use in Research and Breeding}

Current "Rose Genome Sequence Initiative" members:

F. Foucher, L. Hibrand-Saint Oyant,

H. Nybom

L. Hamama and S. Sakr

IRHS, INRA, Agrocampus-Ouest

University of Angers

Angers

France

S. Baudino and J.P. Caissard

BvPAM, University of St Etienne

St Etienne

France

SLU Alnarp

Sweden

S.C. Hokanson

University of Minessota

USA

J.M.S. Smulder

Wageningen UR Plant Breeding

Wageningen

The Netherlands

D.M. Byrne

Texas A\&M University

USA

B. Desnoyé

UMR BFP, INRA

Bordeaux

France

T. Debener

Institute for Plant Genetics

Leibnitz University Hannover

Hannover

Germany

A. Bruneau

Montreal Botanical Garden

Canada

S. Matsumoto

Nagoya University

J. De Riek

Japan

ILVO

Melle

Belgium

K. Yamada

Chubu University

Japan

A. Torres, T. Millan and I. Amaya

IFAPA

P. Wincker

Spain

D. Zamir

Hebrew University of Jerusalem

Israel

Genoscope, CEA

Evry

France

D. Sargent

Genomics and Biology of Fruit Crop Department

S. Michele all'Adige

Italy

J. Gouzy

LIPM, INRA

Toulouse

France

M. Bendahmane, O. Raymond, P. Vergne, A. Dubois and J. Just RDP, INRA-ENS

Lyon

France

Keywords: Rosa, genomics, 'Old Blush', heterozygous, ornamental

Abstract

Rose is one of the most economically important ornamental crops worldwide. Rosa sp. can become a model for woody ornamentals. Its genome size is relatively 
small (560 Mb), its genetic history with ploïdy events is well documented, and rose has a short life for a woody plant. Furthermore, different tools are available, including transcriptomic tools, genetic maps and genetic transformation protocols. Rose represents an original model for studying some ornamental traits that cannot be addressed in other model plant species such as Arabidopsis. Some of these traits, such recurrent blooming, flower morphogenesis or scent production and emission, are of economic interest. Different groups involved in rose genetics and genomics gathered to form the 'Rose Genome Sequence Initiative'. Our objective is to obtain a high quality rose genome sequence of the diploid $R$. chinensis 'Old Blush'. One important issue is the high level of heterozygosity of roses. To tackle this issue, different strategies are proposed: production of a haploid and development a high density genetic map to anchor the genome. This genetic map will be developed from a cross between 'Old Blush' and $R$. wichurana. The genotype $R$. chinensis 'Old Blush' will be sequenced using NGS technologies. The data will be assembled and arranged using the high-density map. In order to increase ESTs and to facilitate genome annotation, we have recently produced ESTs from various tissues of 'Old Blush' under different conditions. Digital expression (RNA Seq) was obtained from the different tissues and data are available on the following web site (https:// iant.toulouse.inra.fr/plants/rosa/FATAL/). The rose genome sequence will be a great step to help identifying the molecular basis of ornamental traits and also to study genetic diversity and genome evolution in the genus Rosa and in the Rosaceae family.

\section{INTRODUCTION}

Rose is the most economically important ornamental crop worldwide (accounting for approximately $30 \%$ of the market) with the top rank for cut flower production and sales as well as being a major garden ornamental and potted flowering plant. Rose is also an important source for perfume and natural oils are extracted from roses (especially $R$. damascena and $R$. centifolia). In different societies, rose is a symbolic plant with a cultural and hedonic importance. Rose, the genus Rosa, is a member of the Rosaceae family, with important crops for fruit (as apple, peach, strawberry) and flower production (as rose). Within the Rosaceae family, rose can become a model for woody ornamental plants. Rose presents different advantages. It has a relatively small genome size (approximately $560 \mathrm{Mbp}$ ). It can be genetically transformed (Debener and Hibrand-Saint Oyant, 2009), even if transformation is still laborious, time-consuming and with low efficiency. For a polycarpic woody plants, rose has a short life cycle: about one year, as seedlings from continuous-flowering roses can flower the same spring. Furthermore, some important processes that can hardly be addressed using model species such as Arabidopsis thaliana, can be studied in the rose. For example, the rose is an ideal model to address recurrent blooming (Iwata et al., 2012; Randoux et al., 2012), flower morphogenesis (i.e., double flower formation (Dubois et al., 2010)), scent biosynthesis and emission, etc. (Scalliet et al., 2008). The rose exhibits a high scent complexity (Kovats, 1987; Shalit et al., 2004). Moreover, some scent biosynthesis pathways are unique or not yet identified in other model species (Kaminaga et al., 2006; Scalliet et al., 2006, 2008).

However, rose is a difficult material for genetic studies. The ploïdy level varied within the genus from diploid to decaploid roses. The majority of cultivated roses are dior-tetraploid. Furthermore rose is highly heterozygous. In a survey of heterozygocity using 32 microsatellites markers, heterozygocity varies from 36 to 87\% (Soules, 2009), with the lowest value for $R$. chinensis var. spontanea and the highest for the old Chinese cultivated genotype 'Single Cerise China'.

To become a model plant for woody perennials, genetics and genomics tools have to be developed. Rose is still in the infancy of genomics when compared to other model plants or crops (as Arabidopsis, rice, maize or strawberry). In the first part of this article, we will present the different genomic resources that have been recently developed and published in rose. In a second part, we will briefly present the rose genome sequencing 
initiative and the perspectives opened by the rose genome sequence.

\section{ROSE GENOMICS TOOLS}

\section{EST and Micro-Arrays Studies}

In the last few years, the main genomic studies in rose were mainly transcriptomic approach. Transcriptomics is the study of the transcriptome, the complete set of RNA transcripts produced by the genome at any on time. Ten years ago, first generation of sequencing was used to produce EST (Expressed Sequence Tags) and discovered new genes. In 2008, around 5,000 unigenes were known in rose, less than $20 \%$ of known genes if we consider that the rose genome contains around 30,000 genes. These EST have been obtained from floral tissues during the floral transition (Foucher et al., 2008) and development (Channelière et al., 2002) and scent production (Guterman et al., 2002). This first series of EST was used to develop microarrays and study the transcriptome during different developmental processes. Using a dedicated micro-array (350 selected genes printed on a slide), Guterman et al. (2002) compared the gene expression during petal development (stages 1 and 4 ) and between perfume and non-perfume rose cultivars ('Fragrant Cloud', FC, and 'Golden Gate', GG, respectively). They identified genes upregulated during FC petal maturation and showed higher expression in FC flowers than in GG. Among those genes, a few were related to secondary metabolism and might code for enzymes involved in scent production such as 2 OMT (O-methyltransferase), a monoterpene synthase, decarboxylase, hydrolases, aminotranferases and aldehyde dehydrogenase (Guterman et al., 2002). This first transcriptomic experiment successfully isolated candidate genes involved in scent production or emission.

Recently, using a Rosa Affymetrix array, with 4,765 unique genes, Dubois et al. (2011) studied the transcriptome during the floral process: from floral induction to early and late floral stage development. This analysis allowed the identification of genes associated with floral induction and development. For floral induction, we have compared the transcriptome at three different stages of two once-flowering roses, $R . \times$ wichurana and $R$. hybrida 'Félicité et Perpétue'. We analyzed genes presenting same expression pattern between both genotypes. We identified already known floral activators (as APETALA1 and SUPPRESSOR OF CONSTANS1 homologues) in agreement with previous reported data (Remay et al., 2009). Furthermore, genes involved in hormone signaling are also regulated, suggested that ethylene and auxin may be involved in floral induction as proposed in other species. During early flower stage development, floral identity genes are up-regulated as AGAMOUS or PISTILLATA homologues, whereas floral identity gene are down-regulated as $S O C 1$.

\section{RNA Seq}

Recently Next Generation Sequencing (NGS) technologies were used to discover new genes and study in silico their expression. Table 1 summarized the results from the two main studies (Dubois et al., 2012; Kim et al., 2012). These two studies contributed largely to increase the number of known unigenes in rose. A French consortium combined 454 and Illumina sequencing technologies to identify new genes from $R$. chinensis 'Old Blush' (Dubois et al., 2012). First, a 454 deep sequencing of 'Old Blush' was done on normalized cDNA libraries from various tissues, allowing after clustering the identification of more than 80,000 unigenes. Using OrthoMCL, we identified peptides that can be clustered into 14,000 protein families. Among them, 50\% were common between rose, woodland strawberry, Prunus and Arabidopsis. Interestingly, 3,500 protein families were specific from rose and may represented rose specific proteins involved in specific processes. Furthermore, we developed a gene expression atlas for $R$. chinensis 'Old Blush'. We performed deep sequencing (Illumina sequencing) of non-normalized cDNA libraries from different tissues (buds, vegetative and floral shoots, flowers, petals, rose hips, roots) in response to biotic and abiotic stresses. From theses sequences, a database for digital expression was developed (http://iant.toulouse.inra.fr/R.chinensis). 
Each sequence obtained was mapped against the 80,000 contigs. By counting the number of positive maps, transcript accumulation for one contig can be estimated (digital expression). For a selection of 23 genes with high or low expression, we validated the digital expression by qPCR (Dubois et al., 2012). In another study, a Korean team analyzed the transcriptome of flower tissues of 4 different rose genotypes: $R$. hybrida 'Vital', 'Maroussia', 'Sympathy' and R. rugosa 'Heading' (Kim et al., 2012). For each genotype, they identified around 14,000 contigs (http:// 210.218.199.249/rose/). The contigs were compared with already known Rosaceae genome sequence as apple, strawberry and peach.

\section{Discovery of Micro RNA}

miRNA are short (20-24 nt) non protein coding RNA, which were demonstrated to play important roles in regulating plant growth and development. miRNA regulate the expression of target mRNA post-transcriptionnaly through either cleavage of the targeted mRNA or translational repression. New sequencing technologies allow the identification of miRNA in non-sequencing organisms. Two recent studies have identified miRNA in rose (Kim et al., 2012; Pei et al., 2013). Using Illumina technology, miRNA libraries from flower tissues (Kim et al., 2012) or from petals treated with ethylene (Pei et al., 2013). To identify the miRNA, two different strategies were used: comparison with known miRNA or use of the $F$. vesca genome to identify miRNA precursors. Results obtained are summarized in Table 2. Kim et al. (2012) identified 267 unique miRNA tags. Among them, 25 were novel. Pei et al. (2013) identified 33 conserved miRNA and 47 putative new miRNA. Using RNA Seq, miRNA accumulation was demonstrated to vary during petal development and in response to ethylene treatment (Pei et al., 2013). Furthermore negative correlation for transcript accumulation was shown between miRNA and their target mRNA, suggesting that miRNA/mRNA target module were conserved in rose.

\section{THE ROSE GENOME SEQUENCING INITIATIVE}

The next step in the rose genomic adventure is to obtain a rose genome sequence. It was decided the creation of a rose genome sequencing initiative in order to obtain a high quality sequence of the rose genome. This initiative gathers all teams that are interesting in the rose genome sequence. All teams are welcome to contribute to this goal by participating in developing resources or supporting financially the project.

No homozygous material was available when starting the project. Therefore one of the main issues concerning rose genome sequencing will be to tackle the heterozygocity. The first choice was the selection of a genotype to sequence. We have chosen an old Chinese cultivated rose, $R$. chinensis 'Old Blush'. Different academic teams all over the world use 'Old Blush'. It is an historical genotype, introduced in Europe around 1760, and which has contributed to the introduction of important ornamental traits such as continuous flowering or tea-scent. 'Old Blush' is though to be an inter-specific cross between $R$. chinensis var. spontanea and $R$. odorata var. gigantea (Meng et al., 2011). Furthermore 'Old Blush' has different characteristics that make it a model plant for rose genetic and genomic studies. It is a rapid cycle genotype (as a continuous flowering rose) and highly fertile. Different genetic and genomics resources are available on this genotype as BAC library (Hess et al., 2007), EST (Dubois et al., 2012), F 1 progeny ((Byrne et al., 2007) and see below). A genetic transformation protocol has been developed and functional validation of interest genes is feasible (Vergne et al., 2010). However as all cultivated roses, the level of heterozygocity is high. Using 32 SSR, heterozygocity was estimated to $74 \%$ (Soules, 2009). In order to solve heterozygocity, we proposed different strategy based on development of a high genetic density map and production of haploids.

The first strategy was to develop a high genetic map from a $F_{1}$ progeny developed by INRA (Angers, France). This progeny was obtained from a cross between 'Old Blush' and $R . \times$ wichurana and contains more than $300 \mathrm{~F}_{1}$ individuals. Important ornamental 
traits segregate in this progeny as the mode of flowering (continuous flowering vs. onceflowering), type of flower (double vs. simple flower), flower color (pink vs. white), plant architecture (bushy vs. ground cover) and disease susceptibility to powdery mildew or black spot. To develop the genetic map, two types of markers are used. A first genetic draft was developed using microsatellite markers. The current genetic map contained 40 microsatellite markers for a size of $300 \mathrm{cM}$ (Laurence Hibrand-Saint Oyant, pers. commun.). These SSR markers will help to anchor this new genetic map to previous published maps as the integrated consensus map (Spiller et al., 2011). This new genetic map will be enriched with SNP markers using the WagRhSNP Axiom array, which contains 68,893 SNPs. The SNP genotyping is under progress and this new genetic map will be used to anchor the rose genome sequence. In parallel, a haploid material from 'Old Blush' is under development by French groups (Angers and Lyon).

The next step will be the sequencing and the assembly of the genome. Presently, 'Old Blush' is under sequencing at the Genoscope (Evry, France). The sequencing is supported financially by INRA (France) and 'Pays de la Loire' (Region of France). For the rose annotation, synteny between rose and woodland strawberry, for which genome sequence is available (http://www.rosaceae.org), can be used. The genera Rosa and Fragaria belong to the Rosoideae tribe in the Rosaceae family; and good micro and macro-synteny were demonstrated. At the whole genome, a good correspondence is found between rose linkage groups and strawberry chromosomes. The Table 3 summarizes the results obtained by our group in collaboration with B. Desnoyé (INRA, Bordeaux, unpublished data) and by Israeli team (Gar et al., 2011) . For instance, almost all rose genetic markers of linkage group 1 are located on strawberry chromosome 7 . However few rearrangements exist between both genomes. 15 markers on rose LG2 are located on strawberry chromosome 1 and 16 markers on chromosome 6, whereas 14 markers on rose LG 3 are located on strawberry chromosome 6 (Table 3). The synteny can be used to clone genes as recently demonstrated for the continuous flowering gene in rose and strawberry (Iwata et al., 2012). The micro-synteny was studied at the Rdrl locus (TerefeAyana et al., 2012). The Rdrl locus corresponds to a cluster of TIR-NBS-LRR genes. By sequencing, the authors demonstrated that the cluster was conserved within the genus Rosa (between $R$. multiflora and R. rugosa) but also between Rosa and Fragaria vesca. A similar region exists on chromosome 7 in woodland strawberry even if numerous inversions and translocations were detected between rose and strawberry (Terefe-Ayana et al., 2012).

\section{CONCLUSION}

The rose genome sequence will open a new area for research in rose genetics and genomics. Concerning functional genomics, resources now exist to follow gene expression during developmental processes or in response to biotic or abiotic stresses by RNA Seq (Dubois et al., 2012). It will allow the identification of important genes in these processes. With the rose genome sequence, epigenomic modifications can be studied to detect modifications of the chromatin as DNA methylation or histone acetylation (Rivera and Ren, 2013). Concerning genetic studies, new technologies are now available to develop high-density genetic maps. In crops, re-sequencing (as Genotyping-BySequencing, GBS (Elshire et al., 2011)) is already used in routine and should be soon available for species as roses. The anchorage of genetic maps and rose genome should accelerate the cloning of major genes and QTL, by identifying rapidly candidate genes under the studied locus. In rose, till now, all genetic studies have been done on $F_{1}$ progeny, with a restricted genetic diversity (Byrne, 2009). With new genotyping technologies, genome-wide association studies are now possible in rose, even if studies on linkage disequilibrium are still necessary to define the best strategy: candidate gene vs. genome-wide approach (Hall et al., 2010). The rose genome sequence will give new insights concerning the genetic diversity and the genome evolution within the genus Rosa but also within the Rosaceae family. Genomic comparisons with already sequenced genomes, as apple, peach or strawberry, will help to understand the origin and evolution 
of the Rosaceae genome.

The rose genome will be also an important resource for rose breeders. Markers, associated with a locus, can be rapidly obtained and transferred for molecular assisted selection. Furthermore, with the high density of SNP markers and the decreasing cost of genotyping, it could become feasible to do genomic selection in rose. Genomic selection is used routinely in animals (Meuwissen et al., 2013) and important studies are done to develop this approach in crops. The marker effects are estimated in a genotyped and phenotyped training population and then are used for the estimation of breeding values of interest genotypes. For instance in rose, the selection of adult traits can be done at the seedling stage and therefore greatly accelerating the process of plant selection.

\section{Literature Cited}

Byrne, D.H. 2009. Rose structural genomics. p.353-379. In: K.M. Folta, S.E. Gardiner (eds.), Genetics and Genomics of Rosaceae, vol 6. Springer.

Byrne, D.H., Anderson, N. and Pemberton, H. 2007. The use of Rosa wichurana in the development of landscape roses adapted to hot humid climates. Acta Hort. 751:267274.

Channelière, S., Rivière, S., Scalliet, G., Szecsi, J., Jullien, F., Dolle, C., Vergne, P., Dumas, C., Bendahmane, M., Hugueney, P. and Cock, J.M. 2002. Analysis of gene expression in rose petals using expressed sequence tags. FEBS Letters 515(1):35-38.

Debener, T. and Hibrand-Saint Oyant, L. 2009. Genetics engineering and tissue culture of roses. p.393-409. In: K.M. Folta, S.E. Gardiner (eds.), Genetics and Genomics of Rosaceae, vol 6. Springer.

Dubois, A., Carrere, S., Raymond, O., Pouvreau, B., Cottret, L., Roccia, A., Onesto, J.-P., Sakr, S., Atanassova, R., Baudino, S., Foucher, F., Le Bris, M., Gouzy, J. and Bendahmane, M. 2012. Transcriptome database ressource and gene expression atlas for the rose. BMC Genomics 13:638.

Dubois, A., Raymond, O., Maene, M., Baudino, S., Langlade, N.B., Boltz, V., Vergne, P. and Bendahmane, M. 2010. Tinkering with the C-Function: a molecular frame for the selection of double flowers in cultivated roses. PLoS ONE 5(2):e9288.

Dubois, A., Remay, A., Raymond, O., Balzergue, S., Chauvet, A., Maene, M., Pécrix, Y., Yang, S.-H., Jeauffre, J., Thouroude, T., Boltz, V., Martin-Magniette, M.-L., Janczarski, S., Legeai, F., Renou, J.-P., Vergne, P., Le Bris, M., Foucher, F. and Bendahmane, M. 2011. Genomic approach to study floral development genes in Rosa sp. PLoS ONE 6(12):e28455.

Elshire, R.J., Glaubitz, J.C., Sun, Q., Poland, J.A., Kawamoto, K., Buckler, E.S. and Mitchell, S.E. 2011. A robust, simple genotyping-by-sequencing (GBS) approach for high diversity species. PLoS One 6(5):e19379. doi:10.1371/journal.pone.0019379.

Foucher, F., Chevalier, M., Corre, C., Soufflet-Freslon, V., Legeai, F. and Hibrand-Saint, Oyant, L. 2008 New resources for studying the rose flowering process. Genome 51(10):827-837.

Gar, O., Sargent, D.J., Tsai, C.J., Pleban, T., Shalev, G., Byrne, D.H. and Zamir, D. 2011. An autotetraploid linkage map of rose (Rosa hybrida) validated using the strawberry (Fragaria vesca) genome sequence. PLoS One 6(5):e20463. doi:10.1371/ journal.pone.0020463.

Guterman, I., Shalit, M., Menda, N., Piestun, D., Dafny-Yelin, M., Shalev, G., Bar, E., Davydov, O., Ovadis, M., Emanuel, M., Wang, J., Adam, Z., Pichersky, E., Lewinsohn, E., Zamir, D., Vainstein, A. and Weiss, D. 2002. Rose scent: genomics approach to discovering novel floral fragrance-related genes. The Plant Cell Online 14(10):2325-2338. doi:10.1105/tpc.005207.

Hall, D., Tegstrom, C. and Ingvarsson, P.K. 2010. Using association mapping to dissect the genetic basis of complex traits in plants. Briefings in Functional Genomics 9(2):157-165. doi:10.1093/bfgp/elp048.

Hess, G., Byrne, D.H. and Zhang, H. 2007. Toward positional cloning of everblooming gene $(e v b)$ in plants: a BAC library of Rosa chinensis cv. 'Old Blush'. Acta Hort. 
751:169-174.

Iwata, H., Gaston, A., Remay, A., Thouroude, T., Jeauffre, J., Kawamura, K., Oyant, H.-S. L., Araki, T., Denoyes, B. and Foucher, F. 2012. The TFL1 homologue KSN is a regulator of continuous flowering in rose and strawberry. The Plant Journal 69(1):116-125.

Kaminaga, Y., Schnepp, J., Peel, G., Kish, C.M., Ben-Nissan, G., Weiss, D., Orlova, I., Lavie, O., Rhodes, D., Wood, K., Porterfield, D.M., Cooper, A.J.L., Schloss, J.V., Pichersky, E., Vainstein, A. and Dudareva, N. 2006. Plant phenylacetaldehyde synthase is a bifunctional homotetrameric enzyme that catalyzes phenylalanine decarboxylation and oxidation. Journal of Biological Chemistry 281(33):23357-23366. doi:10.1074/jbc.M602708200.

Kim, J., Park, J., Lim, C., Lim, J., Ryu, J.-Y., Lee, B.-W., Choi, J.-P., Kim, W., Lee, H., Choi, Y., Kim, D., Hur, C.-G., Kim, S., Noh, Y.-S., Shin, C. and Kwon, S.-Y. 2012. Small RNA and transcriptome deep sequencing proffers insight into floral gene regulation in Rosa cultivars. BMC Genomics 13(1):657.

Kovats, E.S. 1987. Composition of essential oils.7. Bulgarian oil of rose (RosaDamascena Mill). Journal of Chromatography 406:185-222.

Meng, J., Fougère-Danezan, M., Zhang, L.-B., Li, D.-Z. and Yi, T.-S. 2011. Untangling the hybrid origin of the Chinese tea roses: evidence from DNA sequences of singlecopy nuclear and chloroplast genes. Plant Syst. Evol. 297(3-4):157-170. doi:10.1007/ s00606-011-0504-5.

Meuwissen, T., Hayes, B. and Goddard, M. 2013. Accelerating Improvement of Livestock with Genomic Selection. Annual Review of Animal Biosciences 1(1):221237. doi:doi:10.1146/annurev-animal-031412-103705.

Pei, H.X., Ma, N., Chen, J.W., Zheng, Y., Tian, J., Li, J., Zhang, S., Fei, Z.J. and Gao, J.P. 2013. Integrative Analysis of miRNA and mRNA Profiles in Response to Ethylene in Rose Petals during Flower Opening. Plos One 8(5). doi:10.1371/journal.pone.0064290.

Randoux, M., Jeauffre, J., Thouroude, T., Vasseur, F., Hamama, L., Juchaux, M., Sakr, S. and Foucher, F. 2012. Gibberellins regulate the transcription of the continuous flowering regulator, RoKSN, a rose TFL1 homologue. Journal of Experimental Botany 63(18):6543-6554. doi:10.1093/jxb/ers310.

Remay, A., Lalanne, D., Thouroude, T., Le Couviour, F., Hibrand-Saint Oyant, L. and Foucher, F. 2009. A survey of flowering genes reveals the role of gibberellins in floral control in rose. Theor. Appl. Genet. 119(5):767-781.

Rivera, C.M., Ren, B. 2013. Mapping Human Epigenomes. Cell 155(1):39-55.

Scalliet, G., Lionnet, C., Le Bechec, M., Dutron, L., Magnard, J.L., Baudino, S., Bergougnoux, V., Jullien, F., Chambrier, P., Vergne, P., Dumas, C., Cock, J.M. and Hugueney, P. 2006. Role of petal-specific orcinol O-methyltransferases in the evolution of rose scent. Plant Physiology 140(1):18-29. doi:10.1104/pp.105.070961.

Scalliet, G., Piola, F., Douady, C.J., Réty, S., Raymond, O., Baudino, S., Bordji, K., Bendahmane, M., Dumas, C., Cock, J.M. and Hugueney, P. 2008 Scent evolution in Chinese roses. Proceedings of the National Academy of Sciences 105(15):5927-5932. doi:10.1073/pnas.0711551105.

Shalit, M., Shafir, S., Larkov, O., Bar, E., Kaslassi, D., Adam, Z., Zamir, D., Vainstein, A., Weiss, D., Ravid, U. and Lewinsohn, E. 2004. Volatile compounds emitted by rose cultivars: Fragrance perception by man and honeybees. Israel Journal of Plant Sciences 52(3):245-255. doi:10.1560/p7g3-ft41-xjcp-1xfm.

Soules, V.A. 2009. Analysis of Genetic Diversity and Relationship in the China Rose Group. Texas A\&M University.

Spiller, M., Linde, M., Hibrand-Saint Oyant, L., Tsai, C.-J., Byrne, D.H., Smulders, M., Foucher, F. and Debener, T. 2011. Towards a unified genetic map for diploid roses. Theor. Appl. Genet. 122(3):489-500.

Terefe-Ayana, D., Kaufmann, H., Linde, M. and Debener, T. 2012. Evolution of the Rdr1 TNL-cluster in roses and other Rosaceous species. BMC Genomics 13(1):409.

Vergne, P., Maene, M., Gabant, G., Chauvet, A., Debener, T. and Bendahmane, M. 2010. 
Somatic embryogenesis and transformation of the diploid Rosa chinensis cv Old Blush. Plant Cell, Tissue and Organ Culture 100(1):73-81.

\section{$\underline{\text { Tables }}$}

Table 1. Unigene discovery in rose using NGS technologies.

Dubois et al., 2012.

(R. chinensis 'Old Blush').

\begin{tabular}{lccc}
\hline & Reads & Lenght $(\mathrm{Mb})$ & Contigs \\
\hline 454 & $1,043,748$ & 288 & \multirow{2}{*}{80,714} \\
Illumina & $9,332,571$ & 300 & \\
\hline dB: http://iant.toulouse.inra.fr/R.chinensis. & &
\end{tabular}

Kim et al., 2012.

(R. hybrida 'Vital', 'Maroussia', 'Sympathy', R. rugosa 'Heading').

\begin{tabular}{lccc}
\hline & Reads & Lenght (Mb) & Contigs \\
\hline 454 & 508,403 & 108 & \\
(value / librairie) & 127,100 & 27 & 13,609 \\
\hline dB: http $/ / 210.218 .199 .249 / \mathrm{rose} /$. & &
\end{tabular}

dB: http://210.218.199.249/rose/.

Pei et al., 2013.

$\mathrm{dB}$ : http://bioinfo.bti.cornell.edu/rose.

Table 2. Micro RNA discovery in rose.

\begin{tabular}{|c|c|c|c|}
\hline $\begin{array}{l}\text { Kim et al } \\
\text { From } 4 \text { d }\end{array}$ & ultivars (') & 'Maroussia', 'Sympathy' & gosa 'Heading'). \\
\hline & sRNA & $\begin{array}{c}\text { Predicted miRNA } \\
\text { against } F \text {. vesca } \text { genome }\end{array}$ & $\begin{array}{l}\text { Predicted miRNA } \\
\text { against miRNA dB }\end{array}$ \\
\hline 454 & $2,574,444$ & 192 (with 33 new) & 137 \\
\hline $\begin{array}{l}\text { Pei et al. } \\
\text { From } 4 c\end{array}$ & $\begin{array}{l}\text { (studied by } \\
\text { libraries frc }\end{array}$ & y) cultivar 'Samantha' & \\
\hline & sRNA & $\begin{array}{c}\text { Predicted miRNA } \\
\text { against } F \text {. vesca genome }\end{array}$ & $\begin{array}{l}\text { Predicted miRNA } \\
\text { against miRNA dB }\end{array}$ \\
\hline Illumina & $5,309,191$ & 47 new miRNA & 33 \\
\hline
\end{tabular}


Table 3. Macro-synteny between rose and woodland strawberry. The results presented are based on unpublished data from Angers (L. Hibrand-Saint Oyant, INRA) and Bordeaux (B. Desnoye, INRA) and published data from Israeli group (Gar et al., 2011). The figures in the table represent common genetic markers between the 7 rose linkage groups $(\mathrm{RG})$ and the $7 F$. vesca chromosmes (FvChr).

\begin{tabular}{|l|c|c|c|c|c|c|c|}
\hline & RG1 & RG2 & RG3 & RG4 & RG5 & RG6 & RG7 \\
\hline FvChr1 & & $\mathbf{1 5}$ & & 1 & 3 & & \\
\hline FvChr2 & 1 & & & 1 & 1 & $\mathbf{2 2}$ & \\
\hline FvChr3 & & & 2 & 3 & 12 & & \\
\hline FvChr4 & & & & 7 & 1 & 1 & \\
\hline FvChr5 & & & & & 1 & & $\mathbf{1 6}$ \\
\hline FvChr6 & 1 & $\mathbf{1 6}$ & $\mathbf{1 4}$ & 1 & & & \\
\hline FvChr7 & $\mathbf{1 6}$ & & 1 & 1 & 1 & 1 & \\
\hline
\end{tabular}


